\title{
Seasonal pattern in the relapses of Crohn's disease and ulcerative colitis in British Columbia
}

\author{
FRANK H ANDERSON MD FRCPC, LECHENG ZENG MD
}

FH ANDERSON, L ZENG. Seasonal pattern in the relapses of Crohn's disease and ulcerative colitis in British Columbia. Can J Gastroenterol 1995;9(2): 113-117. Ulcerative colitis (UC) reportedly has a seasonal variation of exacerbations. No seasonal variation of relapses in Crohn's disease (CD) has been reported. A retrospective study of the monthly distribution in the relapses of inflammatory bowel disease (IBD) demonstrated seasonality in both UC and CD. From 1971-93, 226 patients $(\mathrm{CD}=139, \mathrm{UC}=87)$ with regular follow-ups for at least 13 consecutive months were analyzed. In the study period, 592 relapses occurred in CD patients and 300 in UC patients. The peak relapse seasons were autumn and winter and the lowest was summer, for both $\mathrm{CD}$ and UC. The seasonal pattern was independent of sex. These results support the view that seasonal factors may be involved in the relapse of IBD.

Key Words: Crohn's disease, Inflammatory bowel disease, Relapse, Seasonality, Ulcerative colitis

\section{Exacerbations de la maladie de Crohn et de la colite ulcéreuse selon un rythme saisonnier en Colombie Britannique}

RÉSUMÉ : Les exacerbations de la colite ulcéreuse (CU) feraient l'objet de variations saisonnières. Ce type de variation n'a pas été rapporté dans le cas de la maladie de Crohn (MC). Une étude rétrospective de la distribution mensuelle des rechutes de maladies inflammatoires de l'intestin (MII) a démontré une répartition saisonnière des rechutes de CU et de MC. Entre 1971 et 1993, 226 patients $(\mathrm{MC}=139$ et $\mathrm{CU}=87)$ ayant été suivis régulièrement durant au moins 13 mois consécutifs ont été analysés. Pour la MC et la CU, les saisons de pointe pour les rechutes ont été l'automne et l'hiver, et la saison accompagnée du moins grand nombre d'exacerbations a été l'été. La distribution saisonnière des rechutes était indépendante du sexe. Les résultats corroborent la théorie selon laquelle des facteurs saisonniers pourraient influer sur les rechutes de MII.

Division of Gastroenterology, Department of Medicine, Vancouver Hospital and Health Sciences Centre and University of British Columbia, Vancouver, British Columbia

Correspondence and reprints: Dr FH Anderson, Vancouver Hospital, Room 206, 700 West 10th Avenue, Vancouver, British Columbia V5Z 1L5. Telephone (604) 876-5122,

Fax (604) 875-4429

Received for publication July 15, 1994. Accepted November 21, 1994
Thlammatory BOWEL DISEASE (IBD) is a chronic inflammatory condition of the gastrointestinal tract characterized by remissions and exacerbations. The etiology of the disease remains poorly understood. Various factors have been implicated in the relapse of the disease, including upper respiratory tract infection, gastroenteritis, drug ingestion, emotional depression and microbacterial infections $(1-4)$. The exact cause of a relapse, however, is still speculative.

Seasonality of ulcerative colitis (UC) was first reported by Myszor and Calam (5) in 1984, who noted a peak relapse period from September through February. Subsequently, seasonal variations in UC have been reported in both retrospective and prospective studies (6-9). In contrast, Crohn's disease (CD) has not been reported to run such a periodical course $(5,10)$. Almost all the studies reporting seasonality are from Europe, with little information available from North America $(11,12)$. We report a retrospective study of the monthly variation in symptomatic and endoscopic relapses of IBD in British Columbia. Our results demonstrated a seasonal distribution of exacerbations not only in UC, but also in CD.

There are two broad climatic regions in British Columbia. The Van- 
TABLE 1

Observed versus expected monthly relapses of Crohn's disease and ulcerative colitis

\begin{tabular}{lcccc}
\hline & \multicolumn{2}{c}{ Crohn's disease } & \multicolumn{2}{c}{ Ulcerative colitis } \\
Month & Observed & Expected & Observed & Expected \\
\hline January & 90 & 50.9 & 29 & 26.0 \\
February & 65 & 51.8 & 24 & 26.3 \\
March & 51 & 51.7 & 24 & 26.1 \\
April & 36 & 50.1 & 27 & 25.4 \\
May & 26 & 49.3 & 14 & 24.8 \\
June & 38 & 48.4 & 23 & 24.0 \\
July & 31 & 47.2 & 12 & 23.8 \\
August & 30 & 47.4 & 20 & 24.0 \\
September & 50 & 47.9 & 20 & 24.3 \\
October & 55 & 48.6 & 31 & 24.8 \\
November & 64 & 49.0 & 31 & 25.1 \\
December & 56 & 49.7 & 45 & 25.4 \\
\hline
\end{tabular}

For Crohn's disease (CD), $\chi^{2}(11$ df $)=68.9, P<0.001$. For ulcerative colitis (UC), $\chi^{2}(11$ df $)=30.9, P<0.01$. The expected value for any given month was calculated by dividing the total number of relapses in the study by the total number of follow-up months in the study, and multiplying by the total number of follow-up months for any given month. The data were obtained from 226 inflammatory bowel disease patients $(C D=139$, $U C=87$ ) from 1971-93

couver region is classified as west coast maritime temperate, with cool, wet winters and warm, relatively dry summers. The interior region is classified as continental with cold, dry winters and warm to hot, dry summers.

\section{PATIENTS AND METHODS}

Medical charts were reviewed for 282 patients with IBD $(\mathrm{CD}=168$, $\mathrm{UC}=114$ ) diagnosed from 1954-92 who had been followed by the authors in the Division of Gastroenterology at Vancouver Hospital, Vancouver, British Columbia, a large privately referred practice. Twenty-four patients with a history of less than one year and five patients without documented relapses in $\mathrm{CD}$, and 23 patients with less than a one-year history and four patients without documented relapses in UC were excluded from the study. The remaining 226 patients $(\mathrm{CD}=139$, $\mathrm{UC}=87$ ) were analyzed. In CD patients, the male:female ratio was 59:80 and ages ranged from 17 to 74 years (mean 40). In UC patients, the male:female ratio was 45:42 and ages ranged from 19 to 68 years (mean 38). The diagnoses were based on clinical features, radiological findings, endoscopy and histology.

The patients had regular appointments at one- to three-month intervals and were followed for at least 13 con- secutive months from April 1971 to June 1993. The longest individual follow-up was 247 months (mean 77) for a CD patient and 266 months (mean 83) for a UC patient. Exacerbation of the disease was documented by direct assessment of the patients or by information from the referring physicians. Most patients were on maintenance therapy when the relapses occurred. Total follow-up months for patients with CD and UC were 10,693 and 7189 months, respectively. During this follow-up period, 592 relapses occurred in CD patients and 300 relapses in UC patients.

Relapse: A relapse of IBD was defined as: the recurrence or sudden aggravation of typical symptoms such as diarrhea, abdominal pain or cramps, partial small bowel obstruction (adhesions excluded), blood and pus or mucus in the bowel movements; and the need for more aggressive therapy such as an increased dose of the present medication, the institution of steroid therapy or the institution of bowel rest (total parenteral nutrition, enteral feeding). The relapses were dated as the time the symptoms first occurred based on the patient's history.

Sigmoidoscopy was done in most UC relapse patients. In contrast, $\mathrm{CD}$ relapse patients were diagnosed mainly by the symptoms. Radiological studies, find- ings at sigmoidocolonoscopy and histological features were used as evidence of disease activity whenever they were available. Patients with macroscopically normal mucosa at sigmoidoscopy or colonoscopy and no recurrent evidence showing radiologically, however, were excluded from the relapse definition in this study. Stool cultures were not routinely done for the exacerbations except on suspicion of $\mathrm{mi}$ croorganic infection involvement. Any symptomatic exacerbation occurring in the time period when patients had influenza, obvious emotional depression and antibiotic use was not included in the statistical calculation of relapses in this study; however, no patient studied was excluded at this point.

Statistics: The $\chi^{2}$ goodness of fit test was used for statistical analysis.

\section{RESULTS}

Among the 226 IBD patients, 592 relapses occurred in $\mathrm{CD}$ patients in 10,693 follow-up months, while 300 relapses occurred in UC patients in 7189 follow-up months during the study period. The observed and expected frequency of monthly relapses are shown in Table 1. The expected value for any given month was calculated by dividing the total number of relapses in the entire study period by the total number of follow-up months in the entire study period, which gives an average relapse rate, and multiplying by the total number of follow-up months for any given month (ie, January, February, March, etc). From the results it is apparent that during May, July and August for CD, as well as May and July for UC, the observed numbers of relapses were only 50 to $60 \%$ of the expected number.

For IBD overall (CD and UC together), the highest relapse rate (Figure $1)$ was found in January $\left(\chi^{2}=78.5\right.$, $\mathrm{df}=11, \mathrm{P}<0.001)$. The seasonal ratio of the observed:expected number of relapses was 178:227.3 for spring, 154:214.7 for summer, 251:219.8 for autumn and 309:230.2 for winter. The seasonal peaks were in the autumn and winter $\left(\chi^{2}=59.3, \mathrm{df}=3, \mathrm{P}<0.001\right)$.

The relapse rates of $\mathrm{CD}$ and $\mathrm{UC}$ 


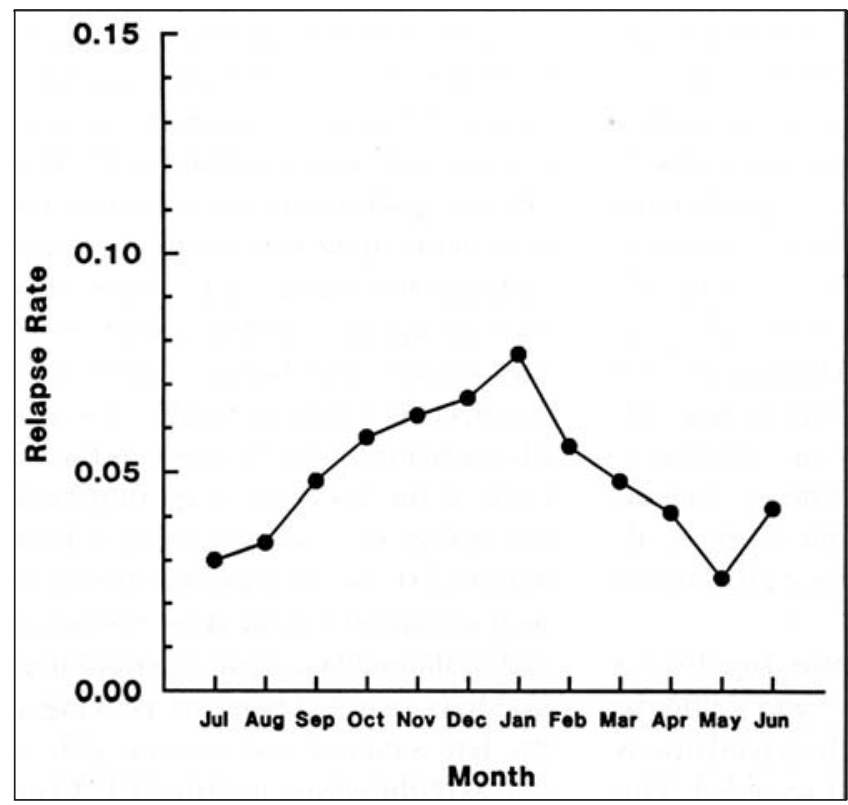

Figure 1) Monthly variation in the exacerbations of inflammatory bowel disease in 226 patients from 1971-93. The relapse rate is equal to the total relapses divided by the total follow-up months of that month

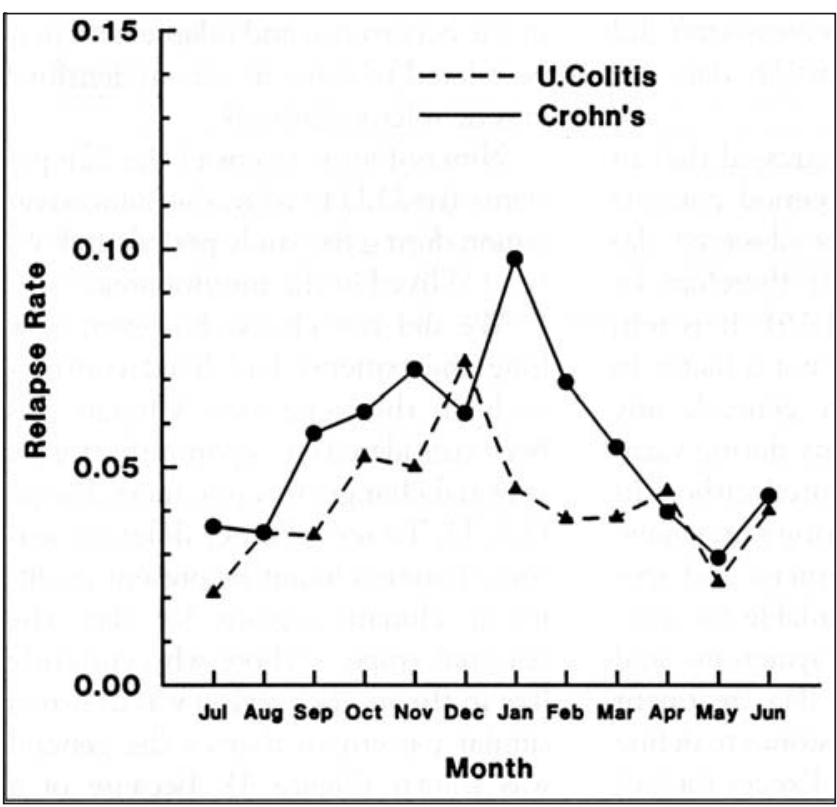

Figure 2) Monthly variation in the exacerbations of Crohn's disease $(n=139)$ and ulcerative colitis $(n=87)$ from 1971-93. The relapse rate is equal to the total relapses divided by the total follow-up months of that month

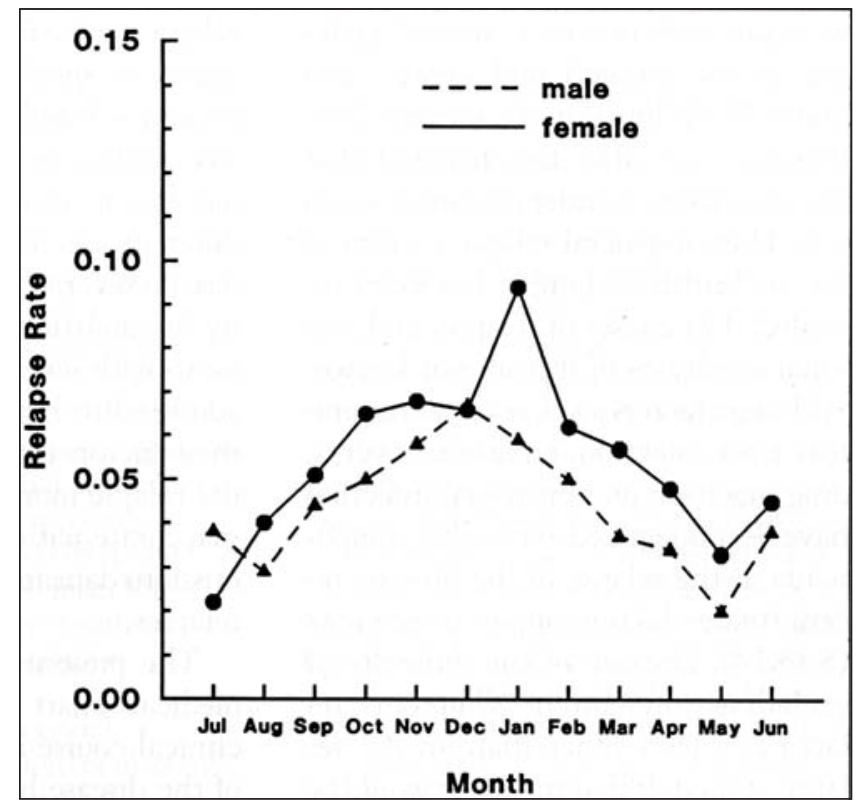

Figure 3) Monthly variation in the exacerbations of inflammatory bowel disease in male $(n=104)$ and female $(n=122)$ patients independently from 1971-93. The relapse rate is equal to the total relapses divided by the total follow-up months of that month

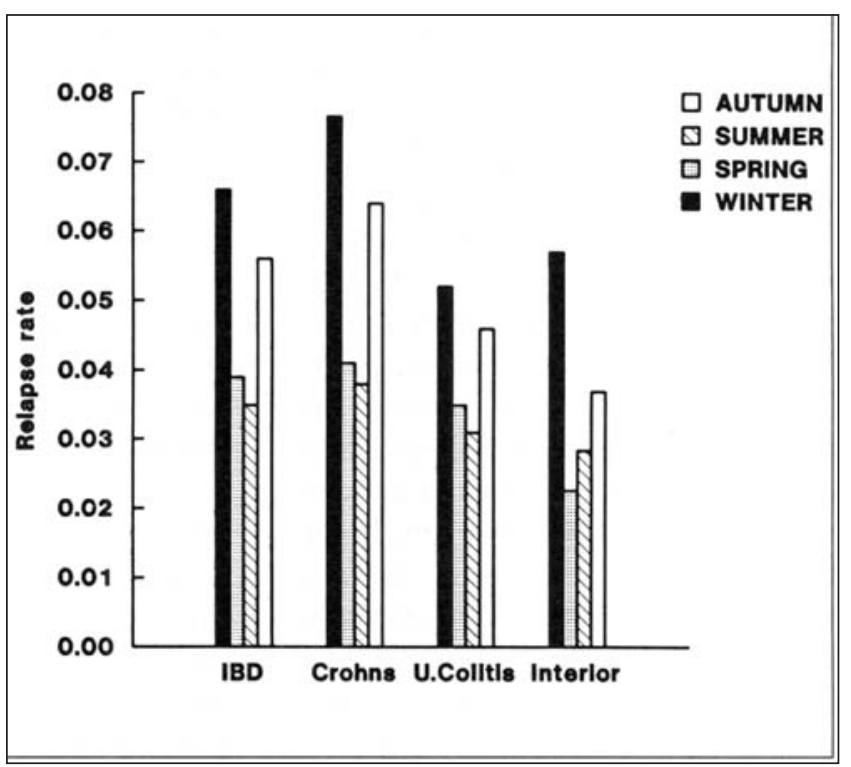

Figure 4) Seasonal variation in the exacerbations of inflammatory bowel disease (IBD) in 226 patients (Crohn's disease $[C D]=139$, ulcerative colitis $[\mathrm{UC}]=87)$ and 13 patients $(\mathrm{CD}=8, \mathrm{UC}=5)$ who lived in the interior region from 1971-93. The relapse rate is equal to the total relapses divided by the total follow-up months of that season peaked in January and December, respectively $(\chi 2=68.9, \mathrm{df}=11, \mathrm{P}<0.001$ for $\mathrm{CD}$, and $30.9, \mathrm{P}<0.01$ for $\mathrm{UC})$. Their seasonal patterns (Figure 2) were similar, with highs in the autumn and winter and lows in the spring and summer $\left(\chi^{2}=49.5, \mathrm{df}=3, \mathrm{P}<0.001\right.$, and 11.7, $\mathrm{P}<0.01$, respectively).
A similar seasonal pattern (Figure 3 ) was found in IBD patients independent of $\operatorname{sex}\left(\chi^{2}=26.0, d f=3, P<0.001\right.$, and 35.8, $\mathrm{P}<0.001$ for males and females, respectively).

The seasonal relapses of total IBD, $\mathrm{CD}$ and UC, and of those who lived in the interior region of British Columbia during the study $(n=13)$ are shown in Figure 4.

\section{DISCUSSION}

The present study demonstrated seasonal changes of relapses not only in $\mathrm{UC}$, but also in CD. The relapse rates were similar between $\mathrm{CD}$ and $\mathrm{UC}$, peaking in the autumn and winter, and 
markedly declining in the summer. Furthermore, we also demonstrated that the seasonality is independent of sex in IBD. Thus, a general relapse pattern of IBD in British Columbia has been revealed. The causes of relapses and seasonal variations of IBD are not known. Although factors such as upper respiratory tract infection, emotional events, drug ingestion and microbial infection have been suggested as possible components in the relapse of the disease, recent studies did not support these views $(8,13,14)$. Because of the difficulty of excluding intercurrent symptoms related to causes other than an IBD relapse, it was felt that the result would be more meaningful if these 'coincidental factors' were excluded. This policy has previously been applied in a similar work by others (15) to depict a seasonal pattern in the incidence of bleeding caused by peptic ulcer, where all possible predisposing factors that might influence the exacerbations were excluded.

Seasonal variation of initial clinical onset of IBD has been reported for CD with peaks in the winter and midsummer, and for UC in autumn and winter $(8,16)$, while seasonal variation of relapses was found in UC but not in CD. There were limitations, however, in those studies reporting no seasonality of CD. Either the number of patients studied was too small (5) or only hospital admission data were analyzed $(10,12)$. In one United States study, seasonal variation of hospital discharges for IBD was initially reported with a trough in the summer, but this pattern was noted to be present not only in IBD but also in all other diseases studied (11). The same authors (12), however, subsequently reported that seasonality was not found in IBD by analyzing the same type of hospitalization data but larger samples and different International Classification of Diseases codes. Patients in these studies were all hospitalized and only represent patients with a certain severity of disease. It is known, however, that most milder relapses of IBD can be treated on an out-patient basis without hospitalization. A relapse can be first managed by a family doctor or specialist in office until the patient is hospitalized for more aggressive treatment. Furthermore, individual doctors or different hospitals have different admitting policies relative to disease severity. There may be variability in admitting milder cases while patients with severe exacerbations will be admitted to hospital immediately. All these factors can affect the counting of the relapse months and bring about an inaccurate pattern if only hospital admissions data are used for analysis of IBD relapses.

The present study was based on a medical chart review and patients' clinical course in which exacerbations of the disease had been recorded. The retrospective design of this study has been strengthened due to the large number of follow-up months as well as relapses available for analysis. Our results support the view that seasonal factors may be involved in the relapse of IBD, similar to other reports that did not use hospital admission data for analysis.

Some studies have stressed that in the summer vacation period patients may be away, and the observed decrease in summer must therefore be carefully assessed $(9,11,16)$. It is felt, however, that this was not a factor in our current study. In general, any change in disease activity during vacation was well documented either directly by us or the referring physicians.

Without any convenient and specific test or marker available for a relapse of IBD, clinical symptoms and patients' responses to IBD treatment were, therefore, the keystones to define a symptomatic relapse. Except for UC, in which sigmoidoscopy was done in most cases, the relapses in most CD cases and a few cases of UC were diagnosed mainly by the symptoms in this retrospective study.

In the gastrointestinal tract, peptic ulcer disease is also characterized by seasonal variation and has been widely studied. The exact cause of its seasonality is likewise elusive. Persistent infection with Helicobacter pylori has recently been found to be associated with recurrent duodenal ulcer. Successful control of the recurrence of peptic ulcer has been reported after the eradication of the microorganism $(17,18)$. H pylori infection is considered to be a chronic gastric mucosal infection and seasonality, however, has neither been reported nor expected to occur. The relationship of $H$ pylori, therefore, to the seasonal variation in peptic ulcer occurrence remains totally unclear. Microorganism involvement in the relapse of IBD has long been suspected, but definitive evidence has not been found (14). Some bacterial infections such as campylobacter (type not specified), salmonella and enterovirus infection have seasonal patterns, peaking in the late summer and autumn (8), as well as in the winter months (19). Considering the similar seasonal patterns between initial symptomatic onsets $(8,16)$ and subsequent relapses of IBD reported in the present and previous studies, it is possible that seasonal or environmental factors may be involved in the occurrence and relapse, and may be related to some as yet unidentified enteric microorganisms.

Ninety-four per cent of the $226 \mathrm{pa}$ tients $(n=213)$ lived in the Vancouver region during the study period, and 6\% $(n=13)$ lived in the interior area.

We did not check, however, how long the patients had lived continuously in the same area. Climate has been considered an important factor for seasonal change of peptic ulcer disease $(20,21)$. To see whether different seasonal patterns might be present in different climate regions for IBD, the seasonal graph of those who currently live in the interior region was drawn; a similar pattern to that of the general was shown (Figure 4). Because of a similar pattern in different climatic regions in our study, as well as those from Europe, climate may not be an important factor for seasonality of IBD. This view supports a previous observation (11). As the number of patients studied in the interior region was small $(\mathrm{CD}=8$, $\mathrm{UC}=5$ ), it will be worthwhile to study a larger group of IBD patients in the interior region. The extent of patient $\mathrm{mi-}$ gration to another city in a different climatic region of British Columbia in this study, as mentioned, is unknown. 


\section{CONCLUSIONS}

The present results reveal a general relapse pattern of IBD in British Columbia, which peaks in the autumn and winter and declines in the summer. This is similar to that of previous European reports and supports the suggestion that seasonal factors may be involved in the relapses of IBD. The cause of the relapse and the seasonality of IBD, however, is unknown, and may be due to other seasonal and environmental factors. Further research on the disease seasonality, with an intensive study on microorganic infections - especially those with seasonal variability - would be worthwhile.

ACKNOWLEDGEMENTS: We thank Mr Douglas Ford for his excellent computer assistance.

\section{REFERENCES}

1. Mee AS, Jewell DP. Factors inducing relapse in inflammatory bowel disease. BMJ 1978;2:801-2.

2. Rampton DS, McNeil NI, Sarner M. Analgesic ingestion and other factors preceding relapse in ulcerative colitis. Gut 1983;24:187-9.

3. Isgar B, Harman M, Whorwell PJ. Factors preceding relapse of ulcerative colitis. Digestion 1983;26:236-8.
4. Newman A, Lambert JR. Campylobacter jejuni causing flare up in inflammatory bowel disease. Lancet 1980;ii:919. (Lett)

5. Myszor M, Calam J. Seasonality of ulcerative colitis. Lancet 1984;ii:522-3.

6. Sellu DP. Seasonal variation in onset of exacerbation of ulcerative proctocolitis. J R Coll Surg Edinb 1986;31:158-60.

7. Karamanolis DG, Delis KC, Kalafatis E, Tsambrinou D, Paspatis G, Xourgias BC. Is there any seasonal distribution in the exacerbation of ulcerative colitis? Gut 1990;31:A1168. (Abst)

8. Riley SA, Mani V, Goodman MJ, Lucas S. Why do patients with ulcerative colitis relapse? Gut 1990;31:179-83.

9. Tysk C, Järnerot G. Seasonal variation in exacerbations of ulcerative colitis. Scand J Gastroenterol 1993;28:95-6.

10. Don BAC, Goldacre MJ. Absence of seasonality in emergency hospital admissions for inflammatory bowel disease. Lancet 1984;ii:1156-7.

11. Sonnenberg A, Wasserman IH. Epidemiology of inflammatory bowel disease among US military veterans. Gastroenterology 1991;101:122-30.

12. Sonnenberg A, Jacobsen SJ, Wasserman IH. Periodicity of hospital admissions for inflammatory bowel disease. Am J Gastroenterol 1994;89:847-51.

13. North CS, Alpers DH, Helzer JE, Spetznagel EL, Clouse RE. Do life events or depression exacerbate inflammatory bowel disease? A prospective study. Ann Intern Med 1991;114:381-6.

14. Weber P, Matthias K, Heizmann WR, Scheurlen M, Jenss H, Hartmann F. Microbic superinfection in relapse of inflammatory bowel disease. J Clin Gastroenterol 1992;14:302-8.

15. Bendahan J, Gilboa S, Paran H, et al. Seasonal pattern in the incidence of bleeding caused by peptic ulcer in Israel. Am J Gastroenterol 1992;87:733-5.

16. Cave DR, Freedman LS. Seasonal variations in the clinical presentation of Crohn's disease and ulcerative colitis. Int J Epidemiol 1975;4:317-20.

17. Hentschel E, Brandstatter G, Dragosics $B$, et al. Effect of ranitidine and amoxicillin plus metronidazole on the eradication of Helicobacter pylori and the recurrence of duodenal ulcer. N Engl J Med 1993;328:308-12.

18. Graham DY. Treatment of peptic ulcers caused by Helicobacter pylori. N Engl J Med 1993;328:349-50.

19. Stubberfield J. Norwalk-like virus linked to gastroenteritis. Clin Diagn Today 1993;3:20.

20. Hall WH, Read RC, Mesard L, Lee LE Jr, Robinette CD. The calender and duodenal ulcer. Gastroenterology 1972;62:1120-4.

21. Bodhe YG, Mokashi RY. Seasonal variation in the incidence of peptic ulcer perforation. Int J Biometeorol 1975;19:85-92. 


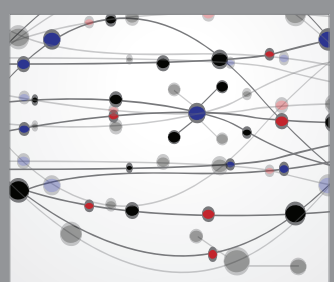

The Scientific World Journal
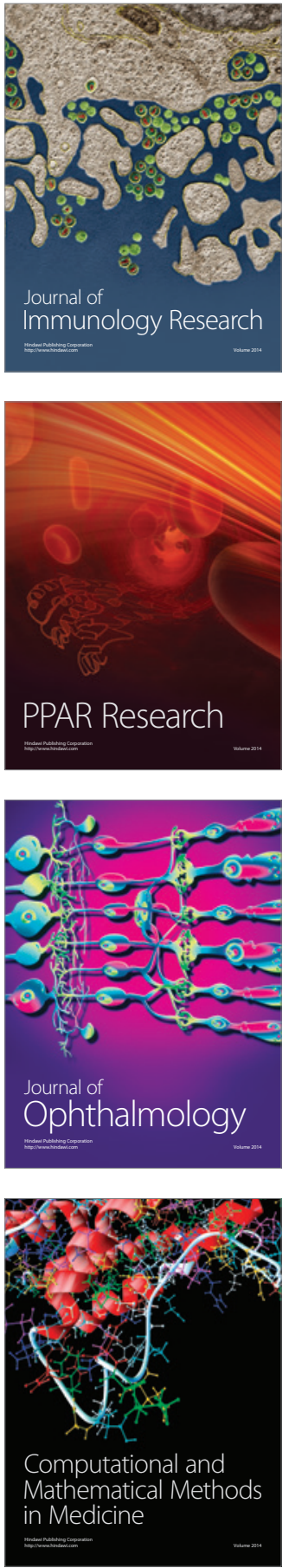

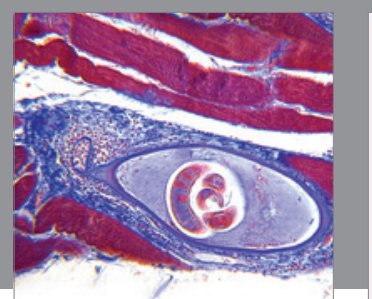

Gastroenterology Research and Practice

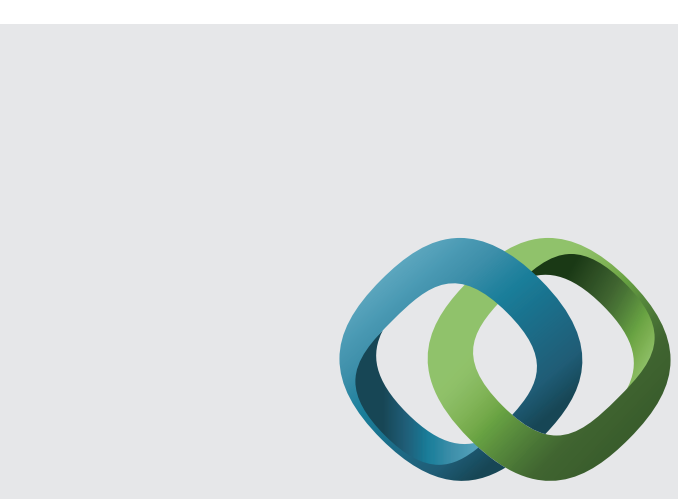

\section{Hindawi}

Submit your manuscripts at

http://www.hindawi.com
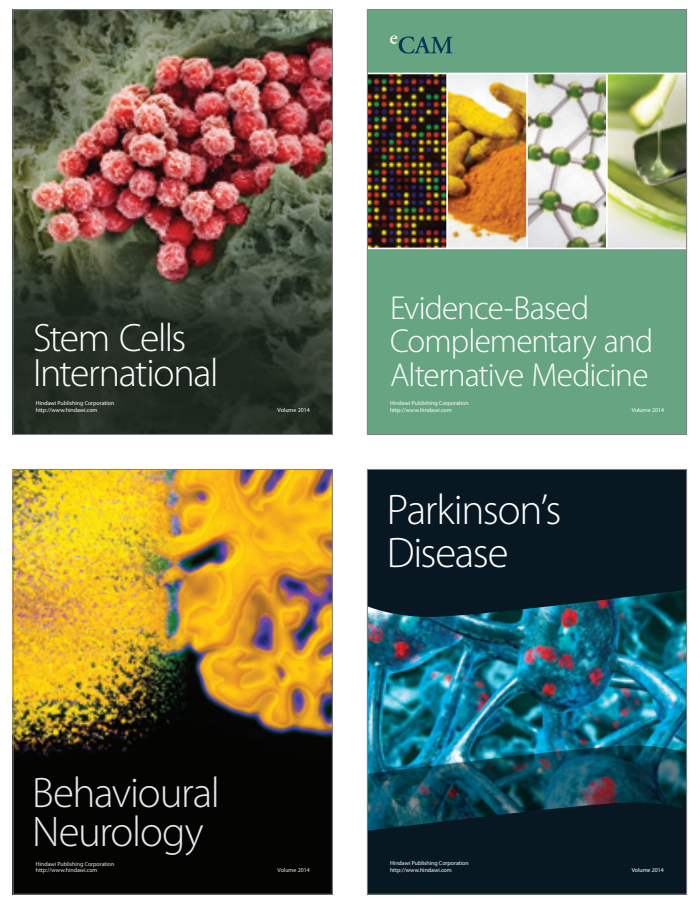
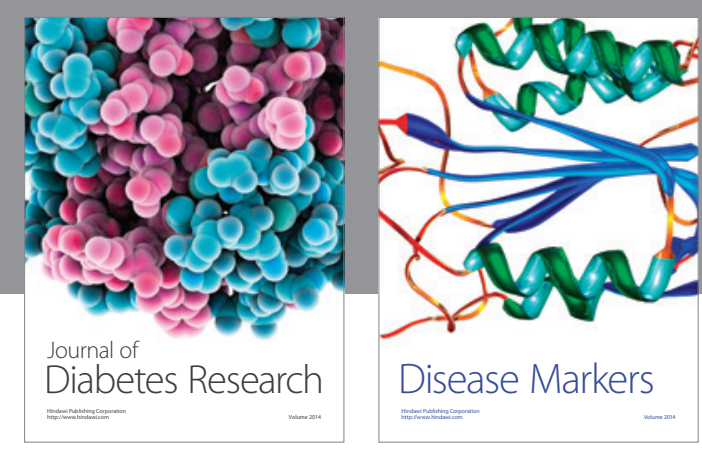

Disease Markers
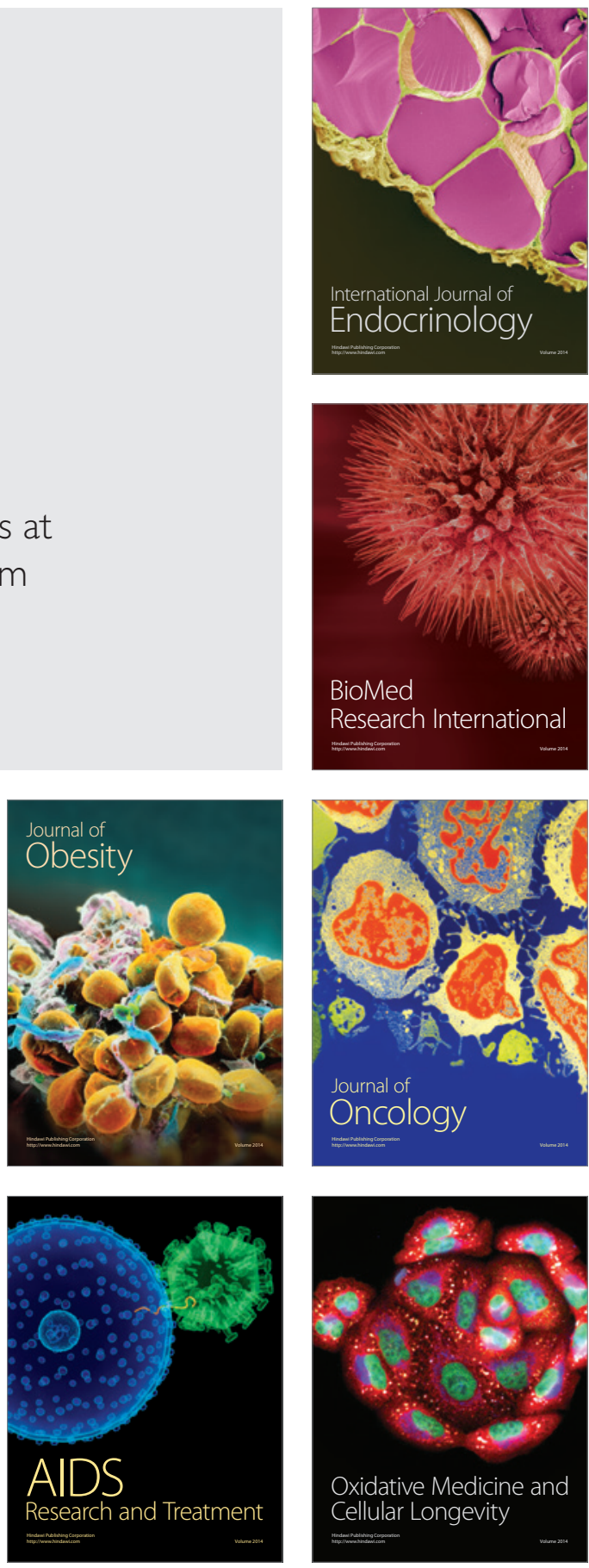